\title{
ESTIMATIVA DO POTENCIAL DE NEUTRALIZAÇÃO DE DIÓXIDO DE CARBONO NO PROGRAMA VIVAT NEUTRACARBO EM TIJUCAS DO SUL, AGUDOS DO SUL E SÃO JOSÉ DOS PINHAIS, PR
}

\author{
Estimate of the potential of carbon dioxide neutralization in the VIVAT \\ NEUTRACARBO program in Tijucas do Sul, Agudos do Sul \\ and Sao Jose dos Pinhais, PR
}

\section{Sylvio Péllico Netto ${ }^{a}$, Érico Emed Kauano ${ }^{\mathrm{b}}$, Márcio Coraiola ${ }^{\mathrm{c}}$, Saulo Henrique Weber ${ }^{\mathrm{d}}$, Sergius Erdelyi ${ }^{\mathrm{e}}$}

\footnotetext{
a'Engenheiro Florestal, Dr., PUCPR, Curitiba, PR, pellico.sylvio@pucpr.br

b Biólogo, PUCPR, Curitiba, PR, erico.kauano@pucpr.br

c Engenheiro Florestal, Dr., PUCPR, Curitiba, PR, marcio.coraiola@pucpr.br

d Matemático, MS., Bolsista CNPq, Curitiba, PR, sauloweber@gmail.com

e Engenheiro Mecânico, IFSE, Tijucas do Sul, PR, ifse@uol.com.br
}

\section{Resumo}

A ação antrópica, principalmente resultante da industrialização, tem provocado mudanças climáticas globais, com inúmeras conseqüências ao ambiente e com repercussões sobre a biodiversidade. As emissões mais nefastas advêm do Dióxido de Carbono $\left(\mathrm{CO}_{2}\right)$ e de outros gases como o Metano $\left(\mathrm{CH}_{4}\right)$ e o Óxido Nitroso $\left(\mathrm{NO}_{2}\right)$, que provocam o aquecimento global. A partir do Protocolo de Quioto, iniciou-se em todos os países do mundo uma ação pública e de toda a sociedade, visando reduzir as emissões e neutralizá-las através de plantios florestais, uma das formas mais eficientes para minorar os fortes efeitos poluidores no ambiente. Foi com este intuito que a PUCPR, através da Aliança Ecológica, estabelecida entre a Instituição Filantrópica Sergius Erdelyi - IFSE, a Associação Paranaense de Cultura - APC e a empresa florestal PANAGRO, lançaram o Programa VIVAT NEUTRACARBO, desenvolvido em Tijucas do Sul, Agudos do Sul e São José dos Pinhais, PR. O Programa tem dois grandes objetivos para combater o aquecimento global: a educação sócio-ambiental e a neutralização de dióxido de carbono, $\mathrm{CO}_{2}$ atmosférico, pela fixação do carbono em reflorestamentos e florestas nativas durante se crescimento. As espécies utilizadas no reflorestamento são: Arancaria angustifolia (Bertol.) Kuntze, Pinus taeda L., Pinus elliottii Engelm, Eucalyptus viminalis Labill., Mimosa scabrella Benth., além de remanescentes florestais nativos (Floresta Ombrófila Mista) em estágio médio a avançado de sucessão secundária. Os resultados obtidos no presente trabalho 
constituem ainda uma primeira aproximação sobre estimativas de neutralização de carbono por florestas plantadas e naturais no Primeiro Planalto Paranaense. Atualmente o programa tem capacidade de neutralizar um total de 962.013,29 ton. de $\mathrm{CO}_{2}$ em 20 anos, dos quais 522.582,97; 15.724,51; $86.308,21 ; 59.184,37 ; 278.213,22$ ton. de $\mathrm{CO}_{2}$ são provenientes das espécies Pinus, Eucalipto, Bracatinga, Araucária e remanescentes de florestas naturais, respectivamente.

Palavras-chave: VIVAT NEUTRACARBO; Neutralização de carbono; Reflorestamento

\begin{abstract}
The antropical action, mainly resultant of industrialization, has provoked global climatic changes, with innumerable consequences to the environment and repercussions on biodiversity. The most ominous emissions happen with Carbon Dioxide $\left(\mathrm{CO}_{2}\right)$ and other gases as Methane $\left(\mathrm{CH}_{4}\right)$ and Nitrous Oxide $\left(\mathrm{NO}_{2}\right)$, which provoke the global heating. From the Kyoto Protocol, a public action was initiated in all the countries of the world and all the society, having aimed at to reduce the emissions and to neutralize them through manmade forests, one of the most efficient ways to mitigate the strong polluting effect in the environment. It was with this intention that the PUCPR, through the Ecological Alliance, established between the Institution Philanthropic Institution Sergius Erdelyi - IFSE, the Parana Culture Association - APC and forest company PANAGRO, had launched Program VIVAT NEUTRACARBO, developed in Tijucas do Sul, Agudos do Sul and Sao Jose dos Pinhais, $P R$. The Program has two great objectives to fight the global heating: the environmental education and the neutralization of carbon dioxide, atmospheric $\mathrm{CO}_{2}$, by fixing the carbon in manmade forests and trough forest growth. The planted species are: Araucaria angustifolia (Bertol.) Kuntze, Pinus taeda L., Pinus elliottii Engelm, Eucalyptus viminalis Labill., Mimosa scabrella Benth., beyond native forest remainders (Mixing ombrophilous Forest) in middle or advanced stage of secondary succession. The obtained results in the present work still constitute a first approach on estimates of carbon neutralization of manmade forests and remained forests in the First Parana Plateau. Currently the program has capacity to neutralize a total of $962,013.29$ ton of $\mathrm{CO}_{2}$ in 20 years, of which 522,582.97; $15,724.51 ; 86,308.21 ; 59,184.37 ; 278,213.22$ ton of $\mathrm{CO}_{2}$ are proceeding from the Pine species, Eucalypti, Bracatinga, Araucaria and remainders of natural forests, respectively.
\end{abstract}

Keywords: VIVAT NEUTRACARBO; Carbon neutralization; Reforestation

\title{
INTRODUÇÃO
}

O desequilíbrio ambiental causado pelos seres humanos nas últimas décadas, principalmente em virtude da emissão de Dióxido de Carbono $\left(\mathrm{CO}_{2}\right)$ e outros gases como o metano $\left(\mathrm{CH}_{4}\right)$ e o óxido nitroso $\left(\mathrm{NO}_{2}\right)$ na atmosfera, vem causando catástrofes, como enchentes e secas, cada vez mais severas. O lançamento desses gases potencializa o efeito estufa, que é um processo natural no Planeta Terra, ocasionando o aquecimento global, tema atual de diversas discussões no mundo todo.

Devido à quantidade com que é emitido, $\mathrm{o} \mathrm{CO}_{2}$ é o gás que mais contribui para o aquecimento global. Suas emissões representam aproximadamente $55 \%$ do total das emissões mundiais de Gases do Efeito Estufa (GEE). O tempo de sua permanência na atmosfera é, no mínimo, de 100 anos. Isto significa que as emissões de hoje têm efeitos de longa duração, podendo resultar em impactos no regime climático, ao longo dos séculos. O Painel Intergovernamental de Mudanças Climáticas (IPCC) concluiu no seu terceiro relatório de avaliação que a temperatura média da atmosfera tem aumentado $0,6^{\circ} \mathrm{C} \pm 0,2^{\circ} \mathrm{C}$ durante o século XX (IPCC, 2007). Evidências científicas apontam que, caso a concentração de $\mathrm{CO}_{2}$ continue crescendo, a temperatura média da terra vai aumentar (entre 1,4 e 5,8 $8^{\circ} \mathrm{C}$ até 2100 ), causando aumento no nível dos mares, efeitos climáticos extremos (enchentes, tempestades, furacões e secas), 
alterações na variabilidade de eventos hidrológicos (aumento do nível do mar, mudanças no regime das chuvas, avanço do mar sobre os rios, escassez de água potável) e colocando em risco a vida na terra (ameaça à biodiversidade, à agricultura, à saúde e bem-estar da população humana) (IPCC, 2007).

A população das cidades é responsável por uma quantia significativa de emissões diretas e indiretas, entretanto as principais poluidoras são as grandes indústrias. Dessa maneira é imprescindível que essas empresas invistam em neutralização de suas emissões. Isso já está sendo feito por algumas empresas, como HSBC e JP Morgan Chase - JPMC, que decidiram cessar suas emissões de $\mathrm{CO}_{2}$ na atmosfera e encorajam seus clientes a fazerem o mesmo. O JPMC anunciou o objetivo de, em três anos, diminuir o gasto de energia e uso de água, além de diminuir as emissões de dióxido de carbono em 5\%. O HSBC comprou 170 mil toneladas de $\mathrm{CO}_{2}$, equivalente em créditos de carbono para neutralizar suas operações no mundo em 2005 (ECOPRESS, 2007). Outras, como a Volkswagen Caminhões, a Interface Carpetes, o banco Bradesco e a concessionária Primo Rossi, têm desenvolvido seus projetos com o Programa Florestas do Futuro da Fundação SOS Mata Atlântica (SOS MATA ATLÂNTICA, 2007).

Desde o início do século XX uma tendência de aquecimento tem sido observada em todo o país, especialmente no inverno, cuja temperatura mínima tem apresentado uma taxa de aquecimento maior que a temperatura máxima. Um indicador de aquecimento é a tendência de haver um maior número de dias mais quentes no inverno, e em menor grau, de um maior número de dias mais quentes no verão e no inverno. Em relação à chuva, a tendência não é muito clara devido a poucos estudos, porém expectativas de aumento na freqüência de extremos de chuva têm sido observadas nas regiões sul e sudeste, e na Amazônia. Entretanto, talvez o mais importante seja a presença de variações interanuais, associadas ao El-niño ou à variabilidade do Atlântico Tropical e Sub-Tropical, e interdecadais associadas à variações naturais de clima (MARENGO, 2007).

\section{Créditos de carbono}

A crescente preocupação com questões ambientais globais e o avanço no estado da arte científica, fez com que a mudança climática fosse introduzida na agenda política mundial em meados da década de 1980, assumindo um papel central com a crescente preocupação acerca de uma possível mudança no padrão de funcionamento do sistema climático (PEREIRA; MAY, 2003).

Em 1992, durante a Rio 92, foi criada a Convenção Quadro das Nações Unidas sobre Mudanças Climáticas. Na Conferência das Partes realizada em 1997, em Quioto no Japão, foi estabelecido um acordo, o Protocolo de Quioto, em que foram definidas metas de redução da emissão de GEE's para os países integrantes, com critérios e diretrizes para a utilização de mecanismos de mercado (ROCHA, 2003).

O protocolo criou o Mecanismo de Desenvolvimento Limpo - MDL, um mecanismo de flexibilização econômica, cuja idéia central consiste em que cada tonelada de $\mathrm{CO}_{2}$ deixada de ser emitida, ou retirada da atmosfera por um país em desenvolvimento, poderá ser negociada no mercado mundial por Reduções Certificadas de Emissões - RCE (ROCHA, 2003; ROCHA, 2006). Assim, o mercado de créditos de carbono no âmbito do MDL pode ser caracterizado como a comercialização de RCE's entre países em desenvolvimento e países desenvolvidos, com metas de redução de emissões definidas pelo Protocolo de Quioto.

\section{Neutralização de carbono}

Partindo do princípio de comercialização de créditos de carbono proposto pelo MDL, foram criados outros mercados de comercialização de créditos de carbono paralelos ao Protocolo de Quioto, entre os quais pode-se citar a Bolsa do Clima de Chicago (CCX), que possui um funcionamento semelhante ao MDL e a Neutralização de Carbono. Tal decisão baseou-se na avaliação pela ONU das reais condições em que os diferentes países se encontram frente suas emissões (Tabela 1).

A neutralização de Carbono pode ser considerada como uma forma de mitigação ambiental, onde empresas e cidadãos têm a possibilidade de compensar suas emissões de CO2 por meio da fixação de carbono realizado por árvores durante o seu crescimento e desenvolvimento. Assim, o CO2 que é lançado na atmosfera é retirado pelas florestas, ou seja, é neutralizado.

Rev. Acad., Ciênc. Agrár. Ambient., Curitiba, v. 6, n. 2, p. 293-306, abr./jun. 2008 
TABELA 1 - Lista da diferença das emissões de gases CFC entre 1990 à 2004 dos principais poluidores segundo a $\mathrm{ONU}$

Table 1 - List of the gases emission difference - CFC - from 1990 to 2004, of the most relevant polluters, according to $\mathrm{ONU}$

\begin{tabular}{lccc}
\hline País & $\begin{array}{c}\text { Diferença entre as } \\
\text { emissõesde CFC } \\
(\mathbf{1 9 9 0 - 2 0 0 4 )}\end{array}$ & $\begin{array}{c}\text { Objetivo da União } \\
\text { Européiapara 2012 }\end{array}$ & $\begin{array}{c}\text { Obrigação do } \\
\text { Tratado 2008-2012 }\end{array}$ \\
\hline Alemanha & $-17,0 \%$ & $-21,0 \%$ & $-8 \%$ \\
Canadá & $+27,0 \%$ & Não assinado & $-6 \%$ \\
Espanha & $+49,0 \%$ & $+15,0 \%$ & $-8 \%$ \\
Estados Unidos & $+16,0 \%$ & Não assinado & Não assinado \\
França & $-0,8 \%$ & $0,0 \%$ & $-8 \%$ \\
Grécia & $+27,0 \%$ & $+25,0 \%$ & $-8 \%$ \\
Irlanda & $+23,0 \%$ & $+13,0 \%$ & $-8 \%$ \\
Japão & $+6,5 \%$ & Não assinado & $-6 \%$ \\
Reino Unido & $-14,0 \%$ & $-12,5 \%$ & $-8 \%$ \\
Portugal & $+41,0 \%$ & $+27,0 \%$ & $-8 \%$ \\
Outros 15 países da UE & $-0,8 \%$ & Não assinado & $-8 \%$ \\
\hline
\end{tabular}

Fonte: IPCC, 2007.

\section{Carbono nas árvores}

As principais formas de mitigação do Aquecimento Global apontadas são atividades de florestamento, reflorestamento e conservação florestal. Segundo o IPCC (2007), as atividades de mitigação relacionadas com as florestas podem reduzir de forma considerável as emissões por fontes e aumentar as remoções de $\mathrm{CO}_{2}$ por sumidouros com custos baixos, podendo ser planejadas para criar sinergias com a adaptação e o desenvolvimento sustentável. O IPCC (2007) aponta adicionalmente, para as atividades florestais, co-benefícios substanciais em termos de geração de empregos, geração de renda, biodiversidade e conservação das bacias hidrográficas, oferta de energia renovável e redução da pobreza.

\section{Referências sobre neutralização de carbono e fotossíntese}

$\mathrm{O}$ fato das florestas poderem reduzir as emissões e aumentar as remoções de $\mathrm{CO}_{2}$ por sumidouros está ligado a dois pontos básicos: a conservação florestal e fixação de carbono. A conservação florestal, efetuada através de planos de manejo, proporciona a fixação de carbono nas árvores por meio do crescimento anual, contrapondo-se às ações de desmatamento e queima, que são fontes de emissões de $\mathrm{CO}_{2}$. A fixação pode ser atribuída, ainda, pelo florestamento e reflorestamento, tanto com fins comerciais, como ambientais, havendo nesses casos uma absorção muito maior, pelo fato das árvores estarem em pleno desenvolvimento e crescimento. Barbosa e Fearnside (1999) calcularam a emissão bruta de gases do efeito estufa liberados por combustão das diversas classes de biomassa, no estado de Roraima, Brasil, em uma área total efetivamente queimada estimada entre $38.144-40.678 \mathrm{~km}^{2}$. Esses autores concluíram que, considerando apenas o emitido por combustão, essa emissão foi de, em milhões de toneladas de gás, 17,3 de $\mathrm{CO}_{2}, 0,21-0,35$ de $\mathrm{CH}_{4}, 1,99-3,68$ de $\mathrm{CO}, 0,001-0,003$ de $\mathrm{N}_{2} \mathrm{O}$, 0,06-0,09 de $\mathrm{NO}_{2}$ e 0,25 de hidrocarbonetos não-metânicos (HCNM).

As árvores têm a capacidade de retirar e fixar carbono da atmosfera por serem, juntamente com outros tipos vegetais, seres fotossintetizantes, que por esse processo sintetizam compostos orgânicos a partir da luz, água e dióxido de carbono, liberando oxigênio no ar e fixando o carbono em sua estrutura.

Muitos estudos têm sido desenvolvidos com a finalidade de quantificar o carbono estocado e fixado por ecossistemas florestais. Tais estudos foram iniciados na Amazônia Brasileira em pesquisas realizadas no Instituto Nacional de Pesquisas na Amazônia (INPA), lideradas por Niro Higuchi, por 
meio da quantificação de biomassa florestal em parcelas experimentais (HIGUCHI et al., 1994). Nessa mesma linha de pesquisa, destacam-se os trabalhos realizados no Pará com quantificação de biomassa florestal em parcelas permanentes (SILVA et al., 1995).

Philips et al. (1998), usando uma estrutura de parcelas permanentes na Floresta Tropical Úmida, concluíram que essas parcelas acumularam aproximadamente 0,71 ton. $\pm 0,34$ ton. de carbono por hectare por ano nas últimas décadas. Os dados ora apresentados sugerem que Florestas Neotropicais representam uma expressiva unidade neutralizadora de carbono, reduzindo a taxa de seu incremento na atmosfera.

Em um experimento de manejo florestal do Instituto Nacional de Pesquisas da Amazônia, no município de Manaus (AM), com parcelas monitoradas desde 1980, verificou-se que ocorre uma acumulação (fixação na árvore) de carbono, de 16 toneladas métricas, resultando em um incremento periódico anual significativo $(\mathrm{p}=0,039)$, em torno de 1,2 t/ha/ano (HIGUCHI et al., 2004).

$\mathrm{Na}$ região sul do país os primeiro estudos sobre biomassa florestal foram realizados na Universidade Federal do Paraná (UFPR), com o apoio do Programa Ecológico de Longa Duração (PELD), e apresentados os primeiros resultados em Sanquetta (2002). Igualmente, na Universidade Federal de Santa Maria (UFSM), o grupo liderado pelo professor Mauro Valdir Schumacher tem trabalhado em avaliação de estoque de carbono em florestas plantadas de Pinus taeda e Acacia mearnsii no Rio Grande do Sul (SCHUMACHER et al., 2002).

\section{Programa VIVAT NEUTRACARBO}

O Programa VIVAT NEUTRACARBO é uma iniciativa da aliança ecológica entre a Instituição Filantrópica Sergius Erdelyi - IFSE, a Associação Paranaense de Cultura - APC mantenedora da Pontifícia Universidade Católica do Paraná - PUCPR e a Panagro Empreendimentos Florestais Ltda.

O Programa possui dois grandes objetivos para combater o aquecimento global: a educação sócio-ambiental e a neutralização de dióxido de carbono - $\mathrm{CO}_{2}$ atmosférico, pela fixação do carbono em reflorestamentos e florestas nativas durante seu crescimento.

De maneira geral, para a neutralização, é realizado o inventário das emissões de determinada atividade humana e em seguida é ofertada a possibilidade de compensar estas emissões pelo $\mathrm{CO}_{2}$ equivalente, que é absorvido durante o desenvolvimento das florestas componentes do programa.

O VIVAT NEUTRACARBO possui uma área total de 4.200 hectares distribuída em propriedades localizadas nos municípios de Tijucas do Sul, Agudos do Sul e São José dos Pinhais, na região metropolitana de Curitiba, sendo composta por reflorestamentos de Pinus (Pinus taeda L. e Pinus elliottii Engelm.), Eucalipto (Eucalyptus viminalis Labill.), Bracatinga (Mimosa scabrella Benth.), Araucária (Araucaria angustifolia (Bertol.) Kuntze), e remanescentes da Floresta com Araucária (Floresta Ombrófila Mista).

\section{Alguns aspectos sobre as espécies avaliadas no programa}

As espécies do gênero Pinus têm uma ampla utilização em reflorestamentos comerciais, sendo uma das principais culturas florestais empregadas no Sul do Brasil. O Pinus elliottii var. elliottii possui uma densidade básica de $0,32 \mathrm{~g} / \mathrm{cm}^{3}$ (HIGA et al., 1973) e um teor de carbono de 0,5.

Para o Pinus taeda L. pode-se considerar uma densidade básica de $0,36 \mathrm{~g} / \mathrm{cm}^{3}$, média encontrada por Sette Junior et al. (2006), em estudo da captura de carbono orgânico em povoamentos de Pinus taeda L. na região de Rio Negrinho, SC. Em relação ao teor de carbono foi utilizado o valor de 0,5 , determinado no mesmo estudo.

As Florestas Naturais, avaliadas neste estudo, pertencem à Floresta Ombrófila Mista e são compostas por diversas essências florestais nativas, onde a Araucária se destaca. Pelo fato de o presente estudo analisar a floresta como um todo, foi considerado uma densidade básica média de $0,54 \mathrm{~g} / \mathrm{cm}^{3} \mathrm{de}$ espécies florestais devidamente cadastradas no inventário florestal em parcelas permanentes do PELD em Tijucas do Sul, PR, cujas informações foram obtidas em Carvalho (1994) e um teor de carbono de 0,5.

O gênero Eucalyptus, também tem ampla utilização em plantios florestais. De acordo com Paes et al. (2005), para a espécie Eucalyptus viminalis Labill., a densidade básica é de $0,498 \mathrm{~g} / \mathrm{cm}^{3}$ e o teor de carbono 0,422 . 
De acordo com Barrichelo e Foelkel (1975), a Bracatinga (Mimosa scabrella Benth.) é uma espécie característica dos estágios iniciais de sucessão secundária da Floresta com Araucária, possuindo uma densidade básica de $0,513 \mathrm{~g} / \mathrm{cm}^{3}$ e teor de carbono de 0,413 .

A Araucária é a espécie mais característica da Floresta Ombrófila Mista, que também pode ser utilizada como uma alternativa em reflorestamentos comerciais e, considerando o avançado estado de degradação em que a Floresta com Araucária se encontra, o seu plantio torna-se de extrema importância do ponto de vista da conservação da natureza.

A densidade básica média observada por Rolim e Ferreira (1974) para a Araucaria angustifolia (Bertol.) Kuntze é de $0,44 \mathrm{~g} / \mathrm{cm}^{3}$ e o teor de carbono é de 0,441.

O presente estudo foi realizado com o objetivo de estimar a quantidade de biomassa, estoque de carbono e fixação de dióxido de carbono em diferentes tipologias florestais do Programa VIVAT NEUTRACARBO, englobando reflorestamentos de Pinus taeda L e P. elliottii Engelm., de Araucaria angustifolia (Bertol.) Kuntze, de Eucalyptus viminalis Labill., Bracatingais (Formações de Mimosa scabrella Benth.) e remanescentes florestais nativos (Floresta Ombrófila Mista) em estágio médio a avançado de sucessão secundária.

\section{MATERIAL E MÉTODOS}

\section{Área de estudo}

A área de estudo está localizada nos municípios de Tijucas do Sul, Agudos do Sul e São José dos Pinhais, Região Metropolitana de Curitiba, no estado do Paraná (Figura 1). Situa-se geograficamente entre as coordenadas $20^{\circ} 45^{\prime}$ e $26^{\circ} 00^{\prime}$ de latitude Sul e $49^{\circ} 20^{\prime}$ e $49^{\circ} 05^{\prime}$ de longitude Oeste Greenwich.

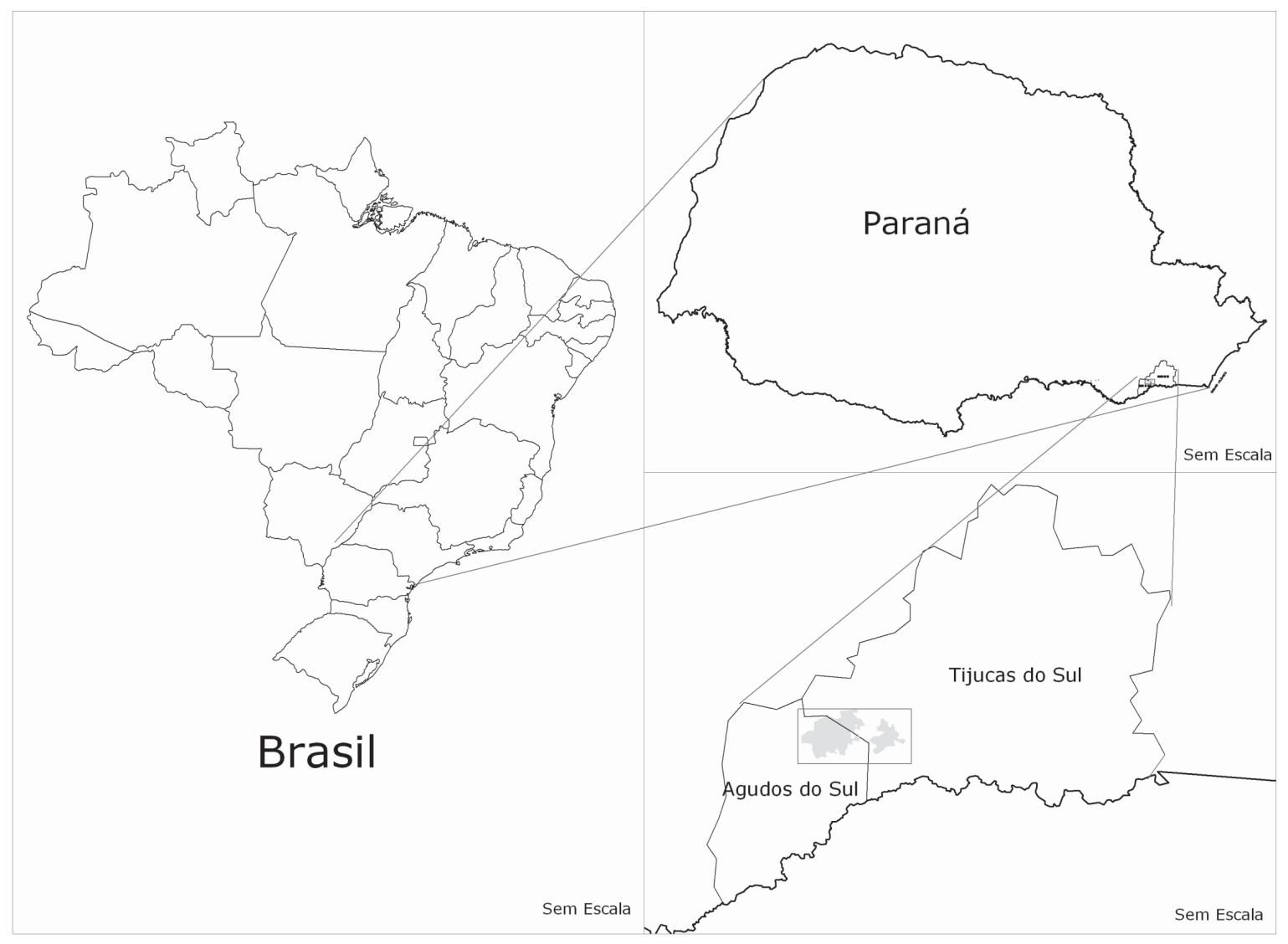

FIGURA 1 - Localização da área de estudo

Figure 1 - The study area localization 
A área de estudo encontra-se no Primeiro Planalto Paranaense, geomorfologicamente originário do mesmo sistema estrutural da Serra do Mar, e constituído, em geral, por blocos de rochas cristalinas suaves e fortemente dobrados, sustentando uma topografia suavemente ondulada a forte ondulada, com colinas de topos amplos e altitudes relativamente uniformes (MAACK, 1968; BIGARELLA, 1978).

O clima predominante na região segundo a classificação de Koppen, é do tipo Cfb, subtropical úmido mesotérmico, de verões frescos e com ocorrência de geadas severas e freqüentes. A temperatura média dos meses mais quentes é inferior a $22^{\circ} \mathrm{C}$ e a dos meses mais frios é inferior a $18^{\circ} \mathrm{C}$.

A vegetação da região pode ser caracterizada como uma zona de tensão ecológica entre a Floresta Ombrófila Mista (Floresta com Araucária) e a Floresta Ombrofila Densa (Floresta Atlântica) (IBGE, 1992). Estudos de campo, visando uma melhor caracterização dos fragmentos florestais nativos nas áreas em estudo, enquadram estes remanescentes como pertencentes à Formação Floresta Ombrófila Mista.

\section{Estimadores de produção de biomassa e de $\mathrm{CO}_{2}$}

No presente trabalho foram consideradas três etapas:

1. conseguir, a partir de dados amostrais e informações da literatura, a produção total de volume comercial para os povoamentos (no caso específico dos povoamentos de Pinus elliottii e P. taeda no VIVAT Floresta Park foram obtidos os volumes comerciais a partir de dados de inventário) e floresta natural;

2. estimar a produção de biomassa a partir de informações por espécie oriundos de pesquisas de quantificação de biomassa total pelo método destrutivo;

3. calcular o potencial de neutralização de $\mathrm{CO}_{2}$ dos povoamentos de Pinus elliottii e $P$. taeda, Eucalyptus viminalis, Mimosa scabrella e Araucaria angustifolia e remanescentes florestais nativos (Floresta Ombrófila Mista).

Resultante deste acervo informativo e processado para as condições específicas do VIVAT Floresta Park, os seguintes valores de produção comercial em 20 anos foram obtidos: Pinus elliottii e $P$. taeda $\left(554,79 \mathrm{~m}^{3} / \mathrm{ha}\right)$, Eucalyptus viminalis $\left(650,00 \mathrm{~m}^{3} / \mathrm{ha}\right.$, adaptado de Carvalho (1981)), Mimosa scabrella (400,00 $\mathrm{m}^{3} /$ ha, adaptado de Ahrens (1981)) e Araucaria angustifolia $\left(320,00 \mathrm{~m}^{3} / \mathrm{ha}\right.$, estimativas obtidas de plantios de 20 anos de idade no VIVAT Floresta Park, Tijucas do Sul, PR) e remanescentes florestais nativos (Floresta Ombrófila Mista) $\left(80,00 \mathrm{~m}^{3} / \mathrm{ha}\right.$, estimativas tomadas com base nas parcelas permanentes do PELD, Tijucas do Sul, PR).

A percentagem dos componentes folhas, galhos vivos, casca e raiz considerada foi $34,5 \%$ para Pinus (SCHUMACHER et al., 2002a), Eucalipto 25,6\% (SCHUMACHER; WITSCHORECK, 2004), Bracatinga 38,9 \% (adaptado de Baggio e Carpanezzi, 1997) e Araucária 30 \% (SCHUMACHER et al., 2002b) e 30\% para floretas naturais, adaptado das informações experimentais obtidas por Watzlawick et al. (2004) e consideradas as condições amostrais de parcelas permanentes do PELD Site 9, existentes em fragmentos florestais em Tijucas do Sul, PR. A densidade básica do Pinus, de florestas naturais, Eucalipto, Bracatinga e Araucária foram 0,36; 0,54; 0,498, 0,513 e 0,44 g/ $\mathrm{cm}^{3}$, respectivamente, conforme apresentado anteriormente. O teor de carbono considerado foi de $50 \%$ para Pinus e florestas naturais, enquanto que para o Eucalipto, a Bracatinga e a Araucária foi de 42,2; 41,3 e 41,1\%, respectivamente. O período de avaliação considerado foi de 20 anos. No caso específico da Bracatinga foram considerados 3 ciclos de 7 anos (21 anos), com densidade inicial de 2.232 árvores, enquanto que para as demais espécies considerou-se densidade inicial de 1666 para Pinus e Eucalipto, 2.500 para florestas naturais e 1.111 para araucária. O número médio de árvores por hectare considerado foi de 659, 845, 1.416, 2.232 e 400, para Pinus, florestas naturais, Eucalipto, Bracatinga e Araucária, respectivamente, obtidos a partir dos levantamentos e dados registrados na PANAGRO.

A PANAGRO possui 1.061,3; 2.702,64; 25; 200 e 200 ha com cobertura florestal de Pinus, florestas naturais, Eucalipto, Bracatinga e Araucária, respectivamente. 


\section{Estimativa da produção de biomassa de Pinus}

Os povoamentos das espécies Pinus elliottii e P. taeda vêm sendo plantados em Tijucas do Sul e Agudos do Sul pela PANAGRO há mais de 30 anos. A partir de dados de produção volumétrica total e informações adicionais de cálculo de biomassa total foram estimados os valores para o ciclo produtivo em 20 anos, conforme a metodologia apresentada a seguir.

O volume de madeira por hectare de cada horto no corte raso $\left(V_{h a}, \mathrm{~m}^{3}\right)$ foi obtido pela razão entre o volume do horto $\left(V_{\text {horto }}, \mathrm{m}^{3}\right)$ e sua área $(A$, ha) (EQUAÇÃO 01).

$$
V_{h a}=\frac{V_{\text {horto }}}{A}
$$

EQUAÇÃO 01

A partir dos dados de produção (volume de madeira no momento do corte raso $\left(V, \mathrm{~m}^{3}\right) \mathrm{e}$ número de árvores $\left(n_{a r v}\right)$ ), detalhado por horto ou local, foi calculado o volume médio por árvore $\left(\bar{V}, \mathrm{~m}^{3} /\right.$ número de árvores) (EQUAÇÃO 02).

$$
\bar{V}=\frac{V}{n_{a r v}}
$$

O volume médio de cada árvore por ano $\left(\bar{V}_{a n o}, \mathrm{~m}^{3} /\right.$ número de árvores/ano) foi obtido dividindo-se o volume médio por árvore $\left(\bar{V}, \mathrm{~m}^{3} /\right.$ número de árvores) pela idade do corte raso (ICR, anos) (EQUAÇÃO 03).

$$
\bar{V}_{\text {ano }}=\frac{\bar{V}}{I C R}
$$

EQUAÇÃO 03

Para se obter a densidade do povoamento por hectare no momento do corte raso $\left(d_{i c}\right)$ dividiuse o número total de árvores do horto $\left(n_{a r r}\right)$ pela sua área $(A$, ha) (EQUAÇÃO 04).

$$
d_{i c r}=\frac{n_{a r v}}{A}
$$

EQUAÇÃO 04

Foi considerada como densidade inicial do povoamento $\left(\mathrm{d}_{\mathrm{i}}\right) 1666$ árvores por hectare, ou seja, espaçamento $3 \times 2$ metros e mortalidade $(M, \%)$ de $10 \%$. Assim foi possível calcular a quantidade de árvores cortadas nos desbastes (desb arr) (EQUAÇÃO 05).

$$
d e s b_{a r v}=\left(d_{i} \cdot(1-M)\right)-d_{c r} \quad \text { EQUAÇÃO } 05
$$

O número de árvores cortadas em cada desbaste (arv/desb) foi calculado dividindo-se o número de árvores cortadas nos desbastes (des $\left.b_{a r n}\right)$ pelo número de desbastes realizados (desb ${ }_{n}$ (EQUAÇÃO 06).

$$
\operatorname{arv} / \operatorname{des} b=\frac{\operatorname{des} b_{a r v}}{\operatorname{des}_{n}}
$$

EQUAÇÃO 06 
O volume de madeira retirada no $i$-ésimo desbaste $i$, no momento do desbaste $\left(V\right.$ des $\left.b, \mathrm{~m}^{3}\right)$ foi obtido multiplicando-se o número de árvores cortadas em cada desbaste (arv/desb), pela idade do desbaste (desb $b_{\text {idade }}$, anos), pelo volume médio de cada árvore por ano $\left(\bar{V}_{\text {ano }} \mathrm{m}^{3} /\right.$ número de árvores/ano) (EQUAÇÃO 07).

$$
V d e s b_{i}=(a r v / d e s b) \cdot \operatorname{des}_{\text {idade }} \cdot \bar{V}_{\text {ano }} \quad \text { EQUAÇÃO } 07
$$

O volume total $\left(V_{\text {total }}, \mathrm{m}^{3}\right)$ de madeira produzido em cada horto foi obtido pela soma dos volumes desbastados $\left(V\right.$ desb, $\left.\mathrm{m}^{3}\right)$ com o volume de madeira por hectare de cada horto no corte raso $\left(V_{b a}, \mathrm{~m}^{3}\right)$ (EQUAÇÃO 08).

$$
V_{\text {total }}=\sum_{i=1}^{n} V \operatorname{des} b_{i}+V_{h a} \quad \text { EQUAÇÃO } 08
$$

Em que $n$ é o número de desbastes realizados em cada horto.

O Incremento Médio Anual do $i$-ésimo horto $\left(I M A_{i}, \mathrm{~m}^{3} / \mathrm{ano}\right)$ foi calculado por meio da equação 09 , em que $V_{\text {total }}\left(\mathrm{m}^{3}\right)$ é o volume total de madeira produzido em cada horto $\left(\mathrm{m}^{3}\right)$ e ICR é a idade do corte raso (anos).

$$
I M A_{i}=\frac{V_{\text {total }}}{I C R} \quad \text { EQUAÇÃO } 09
$$

Este IMA foi ponderado pela área $\left(I M A_{\text {pond }}\right)$, onde $A_{i}$ é a área (ha) e $I M A_{i}$ é o Incremento Médio Anual do $i$-ésimo horto ( $\mathrm{m}^{3} / \mathrm{ano}$ ) (EQUAÇẪO 10).

$$
I M A_{\text {pond }}=\frac{\sum_{i=1}^{n} A_{i} \cdot I M A_{i}}{\sum_{i=1}^{n} A_{i}} \quad \text { EQUAÇÃO } 10
$$

Em que $n$ é o número de hortos avaliados.

O IMA da biomassa $\left(I M A_{b i o}, \mathrm{~m}^{3} /\right.$ ha/ano) foi calculado por meio da equação 11 , em que se procedeu a multiplicação do IMA ( $\mathrm{m}^{3} /$ ano) pela percentagem dos componentes (\% Comp, \%) (folhas, galhos vivos, casca e raiz) acrescido de uma unidade.

$$
I M A_{b i o}=I M A(\% \text { Comp }+1) \quad \text { EQUAÇÃO } 11
$$

\section{Cálculo do potencial de neutralização de Carbono}

O cálculo do potencial de neutralização de $\mathrm{CO}_{2}$, dos povoamentos de Pinus elliottii e P. taeda, Eucalyptus viminalis, Mimosa scabrella e Araucaria angustifolia e remanescentes florestais nativos (Floresta Ombrófila Mista) encontra-se apresentado a seguir. 
A quantidade de carbono neutralizada em 20 anos ( $C$, ton./ha) foi obtido multiplicando-se o IMA ( $\left.\mathrm{m}^{3} / \mathrm{ano}\right)$ pela densidade básica $\left(d_{\text {basica }}, \mathrm{g} / \mathrm{cm}^{3}\right)$ pelo teor de carbono $(\% C, \%)$ pelo período de avaliação, pela percentagem dos componentes (\% Comp, \%) acrescida de uma unidade (EQUAÇÃO 12).

$$
C=I M A \cdot d_{\text {basica }} \cdot \% C \cdot P_{\text {aval }} \cdot(\% \operatorname{Comp}+1) \quad \text { EQUAÇÃO } 12
$$

Multiplicando-se o resultado anterior por 3,666, em função da conversão de carbono em $\mathrm{CO}_{2}$, resultando em sua quantidade em ton/ha neutralizada em 20 anos (EQUAÇÃO 13).

$$
\mathrm{CO}_{2}=\mathrm{C} \cdot 3,666 \quad \text { EQUAÇÃO } 13
$$

A produção de $\mathrm{CO}_{2}$ por árvore $\left(\mathrm{CO}_{2 a r v}\right.$, ton./árvore) foi obtida dividindo-se a quantidade $\mathrm{CO}_{2}$ (ton./ha) pelo número médio de árvores por hectare ( $n_{a r r}$ número de árvores/ha) (EQUAÇÃO 14).

$$
C \mathrm{C}_{2 a r v}=\frac{\mathrm{CO}_{2}}{\bar{n}_{a r v}} \quad \text { EQUAÇÃO } 14
$$

O número de árvores necessárias para produzir uma tonelada de carbono $\left(C_{a r r}\right)$ é o inverso da produção de $\mathrm{CO}_{2}$ por árvore $\left(\mathrm{CO}_{2 a r v}\right.$, ton./árvore) (EQUAÇÃO 15).

$$
C_{a r v}=\frac{1}{C O_{2 a r v}}
$$

A neutralização atual de $\mathrm{CO}_{2}$ em 20 anos $\left(\mathrm{CO}_{2 \text { atuap }}\right.$ ton/20 anos) consiste no produto entre a quantidade $\mathrm{CO}_{2}$ de neutralizada em 20 anos pela área total de produção ( $A_{\text {pord }}$ ha) (EQUAÇÃO 16).

$$
\mathrm{CO}_{2_{\text {atual }}}=\mathrm{CO}_{2} \cdot \mathrm{A}_{\text {prod }} \quad \text { EQUAÇÃO } 16
$$

\section{RESULTADOS E DISCUSSÃO}

\section{Estimadores volumétricos e de produção para as espécies Pinus elliottii e P. taeda}

Na Tabela 2 estão apresentadas as informações resumidas de cada horto de produção da PANAGRO EMPREENDIMENTOS FLORESTAIS LTDA, com dados de ano de plantio, idade no momento da avaliação (anos), produção em volume de madeira no momento do corte raso $\left(\mathrm{m}^{3}\right)$, área (ha), volume de madeira produzida por hectare $\left(\mathrm{m}^{3} / \mathrm{ha}\right)$, calculado por meio da equação 01 e o número de árvores, bem como o volume médio de madeira por árvore.

Considerou-se que foram realizados 2 e 3 desbastes para hortos com menos de 29 e mais de 29 anos e idade de corte raso, respectivamente. Os desbastes foram realizados aos 8, 15 e 22 anos, com rotações entre 21 e 31 anos.

$\mathrm{Na}$ Tabela 3 estão apresentados os volumes médios por árvore ( $\mathrm{m}^{3} /$ árvore), calculado pela equação 02; o número de árvores por hectare; número de árvores cortadas nos desbastes por hectare por horto, calculado por meio da equação 06. 
Estimativa do potencial de neutralização de dióxido de carbono no programa VIVAT NEUTRACARBO em Tijucas do Sul, Agudos do Sul e São José dos Pinhais, PR

TABELA 2 - Dados de produção de madeira da PANAGRO Empreendimentos Florestais LTDA Table 2 - Data of wood production from PANAGRO Forest Company LTDA

\begin{tabular}{|c|c|c|c|c|c|c|}
\hline Local/Horto & Ano/plantio & $\begin{array}{l}\text { Idade } \\
\text { (anos) }\end{array}$ & $\begin{array}{l}\text { Volume no } \\
\text { corte raso }\left(\mathrm{M}^{3}\right)\end{array}$ & Área (ha) & $\begin{array}{l}\text { Volume/ha } \\
\left(\mathrm{m}^{3} / \mathrm{ha}\right)\end{array}$ & $\begin{array}{c}\mathbf{N}^{\mathbf{o}} \\
\text { Árvores }\end{array}$ \\
\hline DC10-5(2) & 1982 & 24 & 269 & 0,73 & 368,493 & 511 \\
\hline HF01 - APP & 1975 & 31 & 694 & 2,06 & 336,893 & 895 \\
\hline $\mathrm{HF} 02$ & 1976 & 30 & 1.144 & 1,70 & 672,941 & 1.487 \\
\hline HF10A & 1984-1985 & 21 & 18.396 & 34,66 & 530,756 & 29.679 \\
\hline HF10A - APP & 1984-1985 & 21 & 5.337 & 10,09 & 528,940 & 8.814 \\
\hline HF7B & 1980-1981 & 25 & 6.688 & 18,84 & 354,989 & 8.102 \\
\hline HF7B - APP & 1980-1981 & 25 & 2.029 & 5,67 & 357,848 & 2527 \\
\hline
\end{tabular}

TABELA 3 - Dados de volume médio periódico por árvores, volume médio por árvore por ano, número de árvores por hectare, quantidade de árvores desbastadas, número de desbastes e número de árvores desbastadas por horto

Table 3 - Data of periodic average volume per tree, annual average volume per tree, number of trees per hectare, thinned number of trees, number of thinning and the number of thinned trees per stand

\begin{tabular}{llllrlr}
\hline $\begin{array}{l}\text { Local/ } \\
\text { Horto }\end{array}$ & $\begin{array}{l}\text { V médio / } \\
\text { árvore }\end{array}$ & $\begin{array}{l}\text { V médio/ } \\
\text { árv/ano }\end{array}$ & Árv/ha & Desbaste & N desb & Nárv/desb \\
\hline DC10-5(2) & 0,53 & 0,0219 & 700,00 & 799,40 & 2 & 399,70 \\
HF01 - APP & 0,78 & 0,0250 & 434,47 & $1.064,93$ & 3 & 354,98 \\
HF02 & 0,77 & 0,0256 & 874,71 & 624,69 & 3 & 208,23 \\
HF10A & 0,62 & 0,0295 & 856,29 & 643,11 & 2 & 321,56 \\
HF10A - APP & 0,61 & 0,0288 & 873,54 & 625,86 & 2 & 312,93 \\
HF7B & 0,83 & 0,0330 & 430,04 & $1.069,36$ & 2 & 534,68 \\
HF7B - APP & 0,80 & 0,0321 & 445,68 & $1.053,72$ & 2 & 526,86 \\
\hline
\end{tabular}

A Tabela 4 foi obtida utilizando-se as equações 07,08 e 09, cujo cálculo resultou nos volumes em cada desbaste, corte raso e total, respectivamente, bem como o IMA de cada horto.

TABELA 4 - Dados dos volumes desbastados, corte raso e total

Table 4 - Thinned volume, volume at rotation time and total volume data

\begin{tabular}{|c|c|c|c|c|c|c|}
\hline \multirow[b]{2}{*}{ Local/Horto } & \multirow[b]{2}{*}{$\begin{array}{l}\text { Desb. } \\
18 \text { anos }\end{array}$} & \multirow[b]{2}{*}{$\begin{array}{l}\text { Desb. } 2 \\
15 \text { anos }\end{array}$} & \multicolumn{2}{|c|}{ Volumes } & \multirow[b]{2}{*}{ Total } & \multirow[b]{2}{*}{ IMA } \\
\hline & & & $\begin{array}{l}\text { Desb. } 3 \\
22 \text { anos }\end{array}$ & $\begin{array}{l}\text { Corte } \\
\text { raso }\end{array}$ & & \\
\hline DC10-5(2) & 70,14 & 131,51 & & 368,49 & 570,14 & 23,76 \\
\hline HF01 - APP & 71,03 & 133,19 & 195,34 & 336,89 & 736,46 & 23,76 \\
\hline HF02 & 42,72 & 80,10 & 117,48 & 672,94 & 913,24 & 30,44 \\
\hline HF10A & 75,93 & 142,36 & & 530,76 & 749,05 & 35,67 \\
\hline HF10A - APP & 72,18 & 135,35 & & 528,94 & 736,47 & 35,07 \\
\hline HF7B & 141,24 & 264,82 & & 354,99 & 761,04 & 30,44 \\
\hline HF7B - APP & 135,37 & 253,82 & & 357,85 & 747,04 & 29,88 \\
\hline
\end{tabular}




\section{Potencial de neutralização de Carbono}

As estimativas do potencial de neutralização de carbono dos povoamentos de Pinus elliottii e P. taeda, Eucalyptus viminalis, Mimosa scabrella e Araucaria angustifolia e remanescentes florestais nativos (Floresta Ombrófila Mista) estão apresentadas a seguir.

A Tabela 5 consiste na planilha de cálculos para obtenção das neutralizações de carbono para as espécies pinus, eucalipto, bracatinga e araucária, bem como de florestas naturais, baseando-se nas equações 12 a 16.

Com base na Tabela 5 foi possível calcular o número médio de árvores para se obter uma tonelada de carbono em um 20 anos em florestas plantadas e naturais (1,93 e 8,21 árvores, respectivamente).

TABELA 5 - Planilha de neutralização de carbono no VIVAT NEUTRACARBO

Table 5 - Spreadsheet containing the carbon neutralization data of VIVAT NEUTRACARBO Program

\begin{tabular}{|c|c|c|c|c|c|}
\hline & Pinus & Naturais & Eucalipto & Bracatinga & Araucária \\
\hline Produção total /ha (m³/ha/ 20 anos) & 554,79 & 80,00 & 650,00 & 400,00 & 320,00 \\
\hline IMA $\left(\mathrm{m}^{3} / \mathrm{ha} / \mathrm{ano}\right)$ & 27,74 & 4 & 32,5 & 20 & 16 \\
\hline $\begin{array}{l}\text { Percentagem dos componentes } \\
\text { (folhas, galhos vivos, casca e raiz) }\end{array}$ & 0,345 & 0,3 & 0,256 & 0,389 & 0,3 \\
\hline IMA da biomassa $\left(\mathrm{m}^{3} / \mathrm{ha} / \mathrm{ano}\right)$ & 37,31 & 5,20 & 40,82 & 27,78 & 20,80 \\
\hline Densidade básica $\left(\mathrm{g} / \mathrm{cm}^{3}\right)$ & 0,36 & 0,54 & 0,498 & 0,513 & 0,44 \\
\hline Teor de carbono & 0,5 & 0,5 & 0,422 & 0,413 & 0,441 \\
\hline $\mathrm{CO} 2$ & 3,666 & 3,666 & 3,666 & 3,666 & 3,666 \\
\hline Período de avaliação (anos) & 20 & 20 & 20 & 20 & 20 \\
\hline $\begin{array}{l}\text { Carbono neutralizado em } \\
20 \text { anos (ton/ha) }\end{array}$ & 134,32 & 28,08 & 171,57 & 117,71 & 80,72 \\
\hline Ton CO2 em 20 anos (ton/ha) & 492,40 & 102,94 & 628,98 & 431,54 & 295,92 \\
\hline N. de árvores por hectare (inicial) & 1666 & 2500 & 1666 & 6500 & 1111 \\
\hline
\end{tabular}

\section{CONCLUSÕES}

Os resultados obtidos no presente trabalho constituem ainda uma primeira aproximação sobre estimativas de neutralização de carbono por florestas plantadas e naturais no Primeiro Planalto Paranaense, dado a dificuldade de se conseguir informações quantitativas que exigem a destruição total dos indivíduos abordados nas unidades amostrais.

O VIVAT NEUTRACARBO é um programa de neutralização de carbono já em funcionamento em Tijucas do Sul, Agudos do Sul e São José dos Pinhais, PR, criado pela aliança ecológica formada entre a IFSE, a APC, a PUCPR e a PANAGRO.

A neutralização de carbono será efetuada por meio de reflorestamentos com as espécies Pinus elliottii, P. taeda, Eucalyptus viminalis, Araucaria angustifolia, Mimosa scabrella e remanescentes florestais nativos (Floresta Ombrófila Mista) em estágio médio a avançado de sucessão secundária, onde se tem como meta neutralizar 1.200 .000 ton. de $\mathrm{CO}_{2}$ em 20 anos.

Atualmente o programa tem capacidade de neutralizar um total de $962.013,29$ ton. de $\mathrm{CO}_{2} \mathrm{em}$ 20 anos, dos quais 522.582,97; 15.724,51; 86.308,21; 59.184,37; 278.213,22 ton. de $\mathrm{CO}_{2}$ são provenientes das espécies Pinus, Eucalipto, Bracatinga, Araucária e remanescentes de florestas naturais, respectivamente.

O programa poderá aumentar sua capacidade de neutralizar $\mathrm{CO}_{2}$ por meio de aquisição de sementes e produção de mudas de melhor qualidade e, consequentemente, aumentar os incrementos médios anuais (IMA ha ${ }^{-1} a^{-1}$ ) dos seus diversos plantios. 
Das espécies utilizadas, nas condições produtivas locais, para a neutralização de carbono no Programa VIVAT NEUTRACARBO, estimou-se que são necessárias aproximadamente 1,42; 2,25; 5,17; 1,35; 8,21 árvores de Pinus, Eucalipto, Bracatinga, Araucária e remanescentes de florestas naturais, respectivamente, para neutralização de uma tonelada de carbono em 20 anos, com média de 1,93 árvores para as espécies plantadas e 8,21 para o remanescente nativo.

O VIVAT NEUTRACARBO, incluído como um programa sócio-ambiental, tem como metas principais, além da neutralização de carbono, atender outras funções sociais da floresta, como a proteção da fauna e flora nativas, a proteção da água, a amenização do clima regional, formação de recursos humanos em todos os níveis, realização de pesquisas científicas, educação ambiental, desenvolvimento do eco-turismo, contribuir para a melhoria qualitativa da paisagem, além dos benefícios sociais diretos provenientes da oportunidade de empregos.

\section{REFERÊNCIAS}

AHRENS, S. Um modelo matemático para volumetria comercial de bracatinga (Mimosa scabrella Benth.). In: SEMINÁRIO SOBRE ATUALIZADAS PERSPECTIVAS FLORESTAIS "BRACATINGA UMA OPÇÃO PARA REFLORESTAMENTO," 4., 1981, Curitiba. Anais... Curitiba: Embrapa-CNPF, 1981. p. 77-89.

BAGGIO, A. J.; CARPANEZZI, A. A. Biomassa aérea da bracatinga (Mimosa scabrella Benth.) em talhões do sistema de cultivo tradicional. Boletim de Pesquisa Florestal, n. 34, p. 31-44, 1997.

BARBOSA, R. I.; FEARNSIDE, P. M. Incêndios na Amazônia Brasileira: estimativa da emissão de gases do efeito estufa pela queima de diferentes ecossistemas de Roraima na passagem do evento “el niño" (1997/98). Acta Amazônica, v. 29, n. 4, p. 513-534, 1999.

BARRICHELO, L. E. G.; FOELKEL C. E. B. Utilização de madeiras de essências florestais nativas na obtenção de celulose: Bracatinga (Mimosa bracatinga), Embaúba (Cecropia SP), Caixeta (Tabebuia cassinoides) e Boleira (Joannesia princeps). IPEF, n. 10, p. 43-56, 1975.

BIGARELLA, J. A Serra do Mar e a porção oriental do Estado do Paraná. Curitiba: Governo do Estado do Paraná, Associação de Defesa e Educação Ambiental, 1978.

CARVALHO, P. E. R. Composição e crescimento de um povoamento natural de bracatinga (Mimosa scabrella Bentham.). In: SEMINẤRIO SOBRE ATUALIDADES E PERPECTIVAS FLORESTAIS Bracatinga uma opção para reflorestamento 4., 1981, Curitiba. Anais... Colombo: Embrapa-CNPF, p. 77-90. 1981.

CARVALHO, P. E. R. Espécies florestais brasileiras: recomendações silviculturais, potencialidades e uso da madeira. Colombo: Embrapa, 1994.

ELIAZEL, V. R. Produção de biomassa e crescimento de árvores de Schizolobium amazonicum (Huber) Ducke sob diferentes espaçamentos na região de mata. Árvore, v. 26, n. 5, p. 573-576, 2002.

HIGA, A. R.; KAGEYAMA, P. Y.; FERREIRA, M. Variação da densidade básica da madeira de P. elliottii var. elliottii e P. taeda. IPEF, n. 7, p. 79-91, 1973.

HIGUCHI, N.; SANTOS, J. M.; IMANAGA, M.; YOSHIDA, S. Aboveground biomass estimate for amazonian dense tropical moist forests. Memoirs of the Faculty of Agriculture, v. 30, n. 39, p. 43-54, 1994.

HIGUCHI, N. et al. Dinâmica e balanço do carbono da vegetação primária da Amazônia central, Floresta, Curitiba, v. 34, n. 3, p. 295-304, 2004.

INSTITUTO BRASILEIRO DE GEOGRÁFIA E ESTATÍSTICA - IBGE. Manual Técnico da Vegetação Brasileira. Rio de Janeiro: IBGE, 1992. (Série Manuais Técnicos em Geociências; n. 1). 
INTERGOVERNMENTAL PANEL ON CLIMATE CHANGE - IPCC. Mudança do clima 2007. Geneva: A Base das Ciências Físicas, 2007.

MAACK, R. Geografia física do Estado do Paraná. Rio de Janeiro: José Olympio, 1968.

MARENGO, J. A. Mudanças climáticas globais e seus efeitos sobre a biodiversidade: caracterização do clima atual e definições das alterações climáticas para o território brasileiro ao longo do século XXI. Brasília: Ministério do Meio Ambiente, 2007. (Série Biodiversidade; v. 26).

PAES, J. B.; MORESCHI, J. C.; LELLES, J. G. Avaliação do tratamento preservativo de moirões de Eucalyptus viminalis lab. e de Bracatinga (Mimosa scabrella Benth.) pelo método de substituição da seiva. Ciência Florestal, v. 15, n. 1, p. 75-86, 2005.

PEREIRA, A. S.; MAY, P. H. Economia do aquecimento global. In: MAY, P.; LUSTOSA. M. C.; VINHA, V. Economia do meio ambiente: teoria e prática. Rio de Janeiro: Elsevier, 2003. p. 219-244.

PHILIPS O. L. et al. Changes in the carbon balance of tropical forests: evidence from long-term plots. Science, v. 282, p. 439-442. 1998.

ROCHA, M. T. Aquecimento global e o mercado de carbono: uma aplicação do modelo CERT. Piracicaba: Marcelo Theoto Rocha, 2003.

ROLIM, M. B.; FERREIRA, M. Variação da densidade básica da madeira produzida pela Araucaria angustifolia (Bert.) O. Kuntze em função dos anéis de crescimento. IPEF, n. 9, p. 47-55, 1974.

SANQUETTA, C. R. Métodos de determinação de biomassa florestal. In: SANQUETTA, R. C. et al. As florestas e o carbono. Curitiba: FUPEF, 2002.

SCHUMACHER, M. V. et al. Estoque de carbono em florestas de Pinus taeda e Acacia mearnsii De Wild. Plantadas no estado do Rio Grande do Sul - Brasil. In: SANQUETTA, R. C. et al. As florestas e o carbono. Curitiba: FUPEF, 2002a.

SCHUMACHER, M. V. et al. Quantificação de biomassa e do conteúdo de nutrientes no corte raso de uma floresta de Araucaria angustifolia (Bert.) O. Ktze. na região de Quedas do Iguaçu - PR. Santa Maria: CEPEF/UFSM, ARAUPEL, 2002b. (Relatório Técnico).

SCHUMACHER, M. V.; WITSCHORECK, R. Inventário de carbono em povoamentos de Eucalyptus spp. nas propriedades fumageiras do sul do Brasil: um estudo de caso. In: SIMPÓSIO LATINO AMERICANO DE FIXAÇÂO DE CARBONO, 2., 2004. Curitiba. Anais... Curitiba: FUPEF, 2004.

SETTE JUNIOR, C. R.; NAKAJIMA, N. Y.; GEROMINI, M. P. Captura de carbono orgânico em povoamentos de Pinus taeda L. na região de Rio Negrinho, SC. Floresta, Curitiba, v. 36, n. 1, p. 33-44, 2006.

SILVA, J. N. M. et al. Growth and yield of a tropical rain forest of the Brazilian Amazon 13 years after logging. Forest Ecology and Management, n. 71, p. 267-274, 1995.

SOS MATA ATLÂNTICA. Disponível em: <www.sosma.org.br>. Acesso em: 13 ago. 2007.

WATZLAWICK, L. F. et al. Teores de carbono em espécies da Floresta Ombrófila Mista. In: SIMPÓSIO LATINO AMERICANO DE FIXAÇÃO DE CARBONO, 2., 2004. Curitiba. Anais... Curitiba: FUPEF. 2004. 